\title{
THE INFLUENCE OF INTRACARDIAC BARORECEPTORS ON VENOUS RETURN, SYSTEMIC VASCULAR VOLUME AND PERIPHERAL RESISTANCE
}

\author{
By JOHN ROSS, Jr., CHARLES J. FRAHM AND EUGENE BRAUNWALD
}

(From the Section of Cardiology, Clinic of Surgery, National Heart Institute, Bethesda, Md.)

(Submitted for publication August 10, 1960; accepted November 3, 1960)

The presence of baroreceptors in the walls of the cardiac chambers and the pulmonary vascular bed is now well established, and their function in the reflex control of the circulation has been the subject of a number of investigations (1-11). Action potentials have been recorded from afferent fibers originating in the heart and lungs $(1,2)$, and elevation of pressures within the ventricular chambers (3-9) and pulmonary vascular bed $(4,10,11)$ has resulted in bradycardia (3-10), a decline in systemic arterial pressure $(4-9,11)$, and either apnea $(5,10)$ or hyperpnea $(4,11)$. In a previous report from this laboratory, evidence was presented that the carotid baroreceptors reflexly influence total venous return and systemic vascular volume (12). The present investigations were undertaken to determine whether or not these hemodynamic parameters are also modified by activation of intracardiac baroreceptors. Studies to localize these receptors within the heart were also carried out.

\section{METHODS}

Seventeen dogs weighing from 15.1 to $23.0 \mathrm{~kg}$, average, 17.2 , were anesthetized with morphine $(2 \mathrm{mg}$ per $\mathrm{kg})$, chloralose (48 $\mathrm{mg}$ per $\mathrm{kg}$ ), and urethan (480 mg per $\mathrm{kg}$ ). Following tracheal intubation, a bilateral thoracotomy was performed through the fourth intercostal space and the sternum was transected. Heparin (2 mg per $\mathrm{kg}$ ) was then administered intravenously. The femoral artery was cannulated, large cannulae were inserted into each vena cava through the right atrium, and total body perfusion was carried out with a pump-oxygenator system as described elsewhere (13). Briefly, blood was drained by gravity from the venae cavae into a rotating disc oxygenator and was returned to the femoral artery by means of a roller pump through a recording rotameter (14) which continuously metered the perfusion rate. Systemic perfusion rates ranged from 73 to 109 and averaged $96 \mathrm{ml}$ per $\mathrm{kg}$. Blood temperature was maintained between $34^{\circ}$ and $37^{\circ} \mathrm{C}$ by means of a heating coil around the oxygenator. In $10 \mathrm{dogs}$, measurements of alterations in the volume of blood in the extracorporeal circuit were carried out. Changes in the level of blood in the oxygenator were detected by means of sensing electrodes (15), and blood was added to or removed from a calibrated reservoir so that the volume of blood in the oxygenator remained constant. Alterations in extracorporeal blood volume, which reflected reciprocal changes in the intravascular blood volume, were measured by recording the level in the calibrated reservoir at 1 minute intervals. In 3 animals, intravascular blood was maintained at a constant volume by increasing or decreasing the arterial pump output; with this maneuver the effect of any intervention on venous return could be determined (16). For example, when venous return to the oxygenator diminished, the pump output was decreased manually at a rate sufficient to maintain the volume of the extracorporeal circuit constant.

Pressures were measured in the aorta and the inferior vena cava through catheters inserted into small branches of the femoral artery and vein; pressures in the right and left ventricles were obtained by means of catheters inserted directly through the ventricular walls, and in the left atrium by means of a catheter introduced through a pulmonary vein. All pressures were measured with Statham pressure transducers and were recorded continuously, together with the systemic perfusion rate, on a multichannel oscillograph. Since the systemic perfusion rate was held constant throughout each experiment, any change in arterial pressure reflected an identical change in peripheral resistance.

In order to study the reflex effects of changes in intracardiac pressure, two types of preparations were employed. In the first preparation, utilized in Dogs 14, 15 and 16 (Table I), the aorta was occluded above the coronary arteries, and blood was supplied to the heart through a line which originated between the pump and the flowmeter. Total systemic perfusion rate was held constant. In these experiments, blood entered the left ventricle through a cannula which had been inserted through the apex. The rate of blood flow into the heart, which determined the pressure in the left side of the heart, was regulated by means of a screw clamp on the inflow line. This blood was pumped by the left ventricle into the aortic segment proximal to the occlusive clamp, thence through the coronary circulation, and was returned to the pump oxygenator by means of a large drainage tube placed in the right ventricle via the azygos vein and right atrium. Although this preparation was satisfactory for studying the effects of changes in intracardiac pressures on peripheral resistance, it was unsuitable for the measurement of alterations of intravascular blood volume and 
venous return; when the blood flow to the heart was increased, a significant volume was necessarily diverted from the extracorporeal circuit into the cardiac chambers and pulmonary circulation.

Accordingly, in the second preparation, blood was circulated through the heart by utilizing a separate circuit, entirely isolated from the pump-oxygenator system (Figure 1). Oxygenated blood drained from a reservoir through a cannulated pulmonary vein and into the left side of the heart. In addition to the drainage cannula placed in the right ventricle, a tube was inserted into a segmental pulmonary artery to assure complete emptying of the right heart and pulmonary artery; the blood from these two drainage tubes was collected in an accessory reservoir. Circulation through the lungs was prevented by mass ligation of each hilum. Alterations in pressure in the left side of the heart could be induced by varying the inflow from the reservoir while the ascending aorta was kept clamped. When the inflow of blood to the pulmonary vein was increased, left heart pressures rose, since the only egress of blood was through the coronary bed. Pressure in the right side of the heart could be modified by varying the resistance in the right ventricular and pulmonary arterial drainage lines, since clamping of the lines resulted in a "damming up" of blood in the right side of the heart. When left ventricular systolic pressure was maintained at a level exceeding approximately $70 \mathrm{~mm} \mathrm{Hg}$, the heart continued to beat satisfactorily for several hours. During each experiment, control pressures, extracorporeal blood volume and heart rate were determined for at least 4 minutes, and following each intervention, measurements were recorded continuously for another 4 to 8 minutes. This preparation was employed in 14 dogs, two of which (7 and 8 , Table I) had been subjected to splenectomy several weeks prior to study.

In an effort to define the activity of the intracardiac receptors more precisely, bilateral mass ligation of the carotid bulb was performed in the 3 dogs in which the first preparation was employed and in 10 of the 14 experiments utilizing the second preparation. In 9 of the $10 \mathrm{dogs}$ in the latter group, the aortic baroreceptors were

TABLE I

Hemodynamic effects of changes in intracardiac pressures

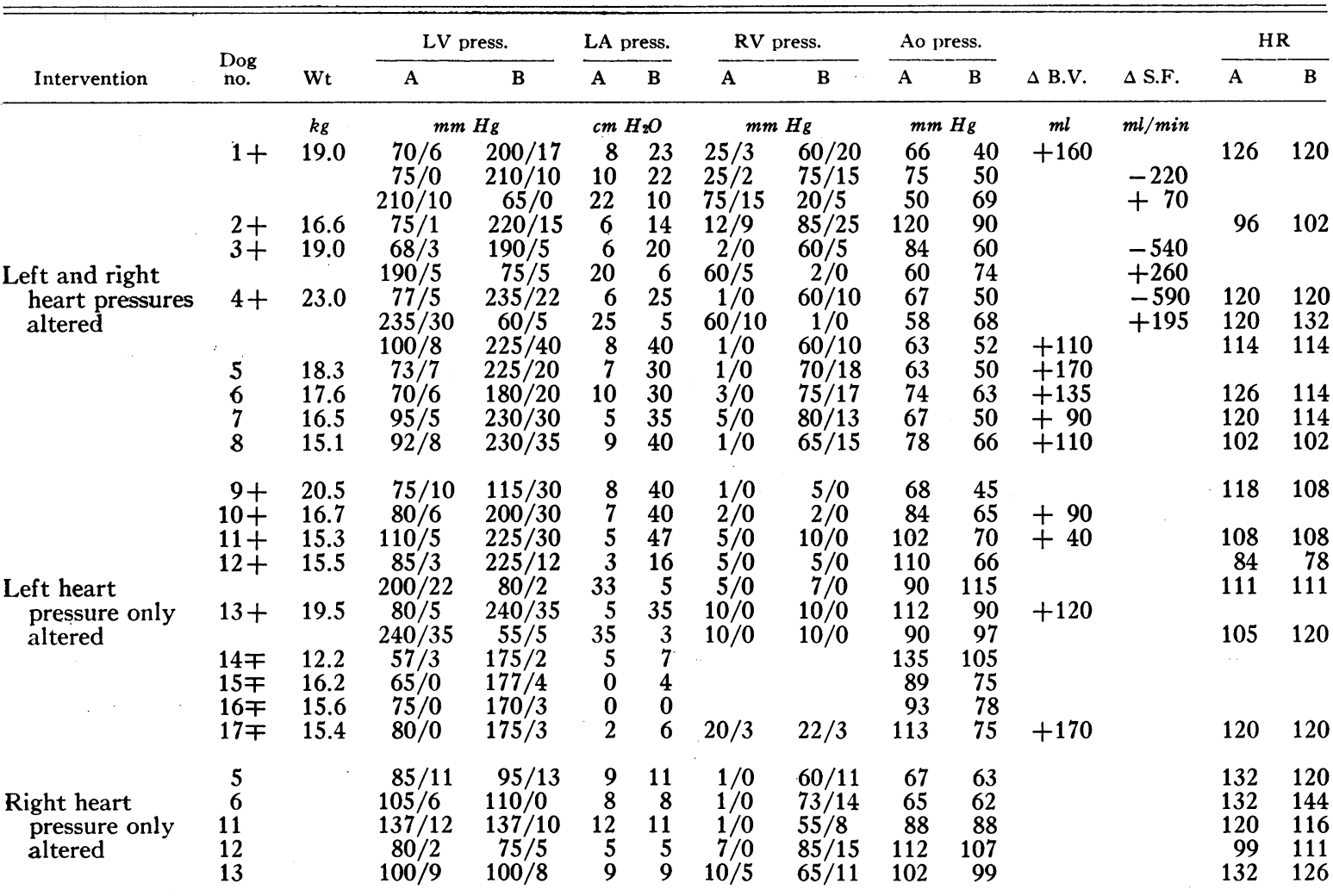

* $\mathrm{LV}=$ left ventricular pressure; $\mathrm{LA}=$ mean left atrial pressure $; \mathrm{RV}=$ right ventricular pressure $;$ Ao $=$ mean aortic pressure; $H R=$ Heart rate in beats per minute. Columns A represent observations during the control period; $B$ represent the observations made following alteration of intracardiac pressure. $\Delta B . V .=$ the change in systemic vascular volume; $\Delta \mathrm{S} . \mathrm{F} .=$ the change in systemic flow $;+=$ carotid and aortic receptors denervated; $\mp=$ carotid receptors only denervated. 


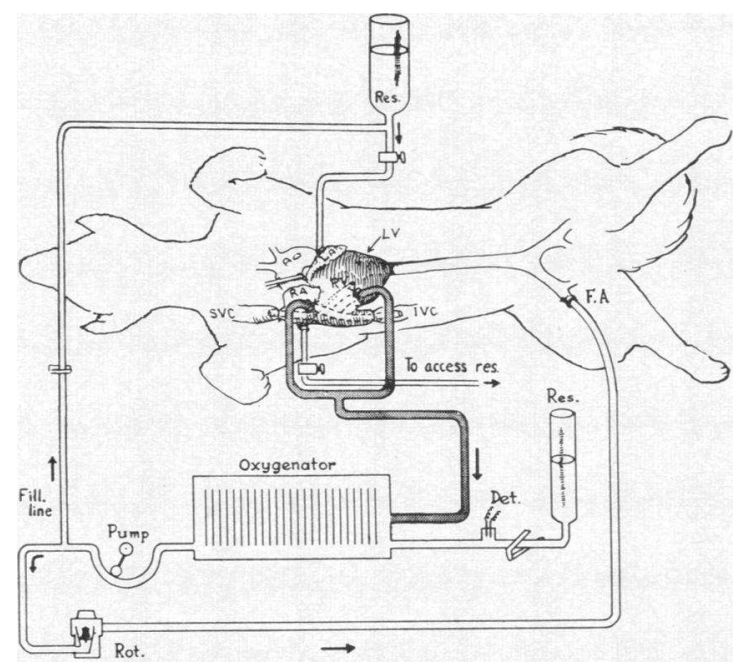

Fig. 1. Schematic RePresentation of the extraCORPOREAL CIRCUIT EMPLOYED. Blood drains by gravity from the superior vena cava (SVC) and the inferior vena cava (IVC) into the oxygenator. The aorta (Ao.) is cross-clamped above the coronary arteries. The level of blood in the oxygenator is sensed by the detecting electrodes (Det.) and blood is added to or withdrawn from the calibrated reservoir (Res.) at the lower righthand corner. Oxygenated blood is pumped through a rotameter (Rot.) into the femoral artery (FA). Intermittently, a clamp on the filling line (Fill. line) is opened to permit replenishment of the top reservoir (Res.) with oxygenated blood.

also removed by stripping the adventitia from the anterior surface of the aorta between the brachiocephalic and subclavian arteries (Table I).

At the conclusion of 6 experiments, the line through which blood entered the left atrium from the reservoir was occluded, resulting in anoxic cardiac arrest or ventricular fibrillation. Alterations in arterial pressure were recorded continuously for several minutes thereafter, while systemic perfusion rate was maintained constant.

\section{RESULTS}

I. Alterations in systemic blood volume. In all ten of the dogs in which blood volume alterations were measured (Table I), elevation of intracardiac pressures resulted in a decline in the extracorporeal volume and, therefore, an augmentation of intravascular blood volume, which ranged from 40 to $170 \mathrm{ml}$ and averaged $120 \mathrm{ml}$. A tracing from an experiment of this type is reproduced in Figure 2. In six of these animals (Dogs 1, 4-8), the pressures in the right side of the heart, the left atrium and the left ventricle were elevated, and in four (Dogs 10,11, 13, 17), the pressure elevation was confined to the left side of the heart, while right heart pressures were not altered. The increments of intravascular volume observed in these two groups of experiments were similar. The changes in blood volume persisted for the entire period that the intracardiac pressure remained elevated, which in some experiments was up to 15 minutes.

II. Alterations in venous return. In Dogs 1,3 and 4 the pressures in both the right and left sides of the heart were elevated. In order to maintain the extracorporeal, and therefore the intravascular, blood volume constant, it was necessary to diminish the output of the pump by 590,540 , and $220 \mathrm{ml}$ per minute; this represented an average decrease of 25.3 per cent from the control systemic perfusion rates. When intracardiac pressures were lowered to their previous levels, venous return increased but did not return to the control levels (Figure 3, Table I).

III. Alterations in systemic vascular resistance. In Dogs 1-8, left ventricular pressure was elevated from average values of $78 / 5$ to $216 / 21 \mathrm{~mm}$ $\mathrm{Hg}$; mean left atrial pressure rose from an average of 7 to an average of $25 \mathrm{~cm} \mathrm{H}_{2} \mathrm{O}$, and right ventricular pressure rose from average values of $6 / 1$ to $69 / 15 \mathrm{~mm} \mathrm{Hg}$. These pressure alterations resulted in a decline in systemic vascular resistance which was maximal approximately 1 minute later. These maximal changes in systemic vascular resistance ranged from 10 to 39 per cent and averaged 24 per cent of the control resistance levels. Subsequently, the arterial pressure returned partially toward control levels (Figures 2 and 4). This return was less prominent in those dogs which had undergone sinoaortic denervation.

In five experiments (Dogs 9-13) right ventricular pressure was maintained constant at a low level (Table I), while left ventricular pressure was elevated from average values of $86 / 6$ to 203/26 $\mathrm{mm} \mathrm{Hg}$, and mean left atrial pressure rose from an average of 6 to an average of $36 \mathrm{~cm}$ $\mathrm{H}_{2} \mathrm{O}$. This again resulted in a decline in systemic vascular resistance which ranged from 20 to 40 per cent and averaged 30 per cent of the control resistance levels.

In four experiments (Dogs 14-17) left ventricular systolic pressure alone was elevated. Pressure in this chamber rose from average values of $69 / 1$ to $175 / 3 \mathrm{~mm} \mathrm{Hg}$, while left atrial 

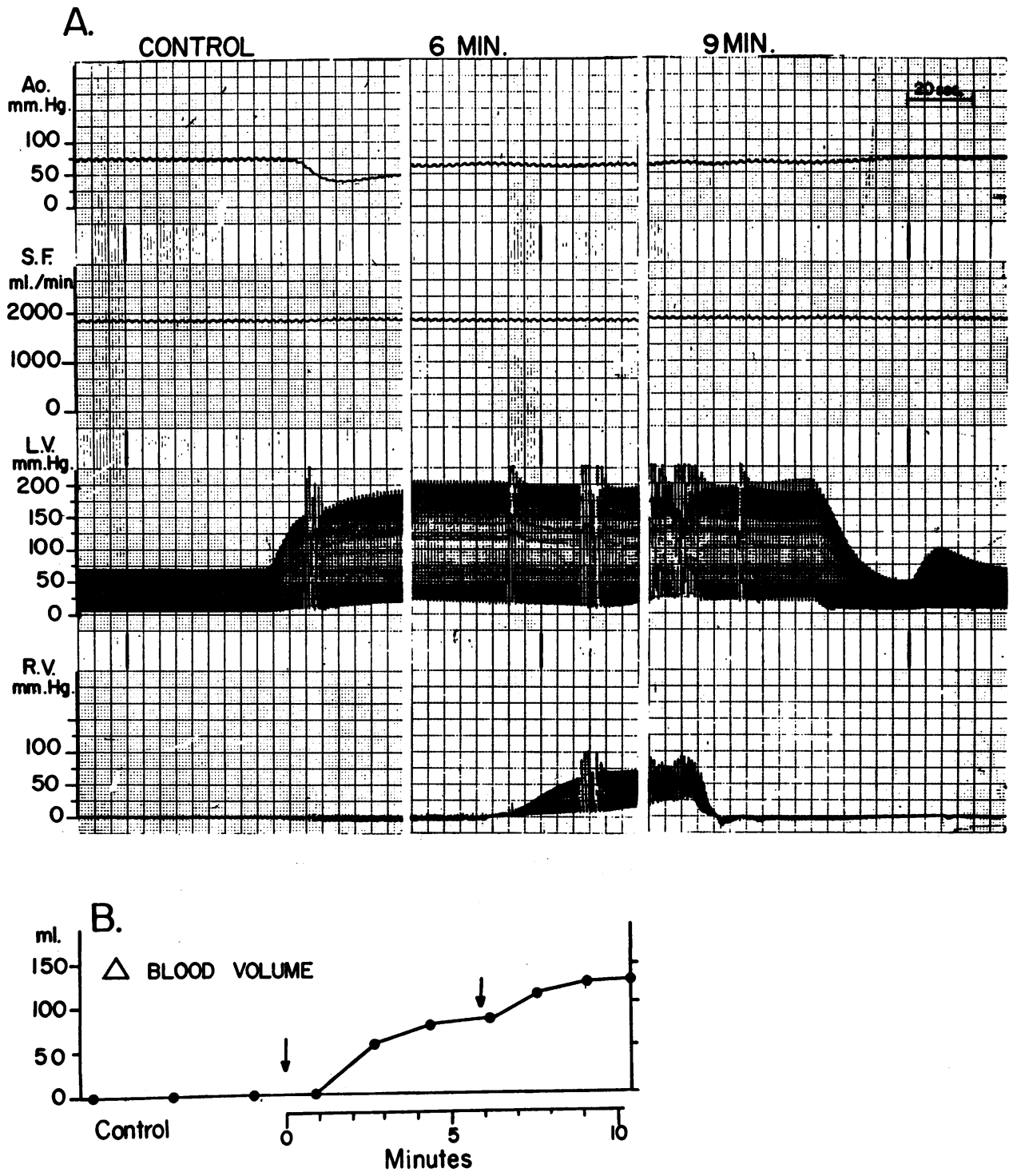

Fig. 2. Dog 6. A. Recordings, from above downward, of pressure in the aorta (Ao.), SYSTEMIC FLOW (S.F.), PRESSURES IN THE LEFT VENTRICLE (LV) AND RIGHT VENTRICLE (RV). In the panel on the left, left ventricular pressure was elevated. Six minutes later, in the center panel, right ventricular pressure was also elevated. In the panel on the right, ventricular pressures were lowered.

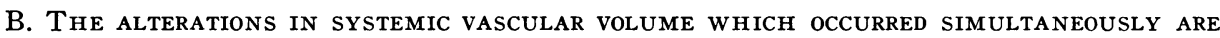
DEPICTED. The vertical arrows indicate the points in time at which left and then right ventricular pressures were elevated.

pressure remained low and changed little or not at all. In all of these dogs the right ventricle was decompressed with a large drainage cannula, and in the one dog in which right ventricular pressure was measured, it did not rise. These elevations in left ventricular systolic pressure alone resulted in a decline in systemic vascular resistance which ranged from 16 to 38 per cent (average, 23) of the control resistance levels (Figure 4). In two other experiments when left ventricular systolic pressure was elevated from levels below $70 \mathrm{~mm}$ $\mathrm{Hg}$ to systolic pressures of 131 and $150 \mathrm{~mm} \mathrm{Hg}$, systemic vascular resistance declined 9.6 and 11.8 per cent. 


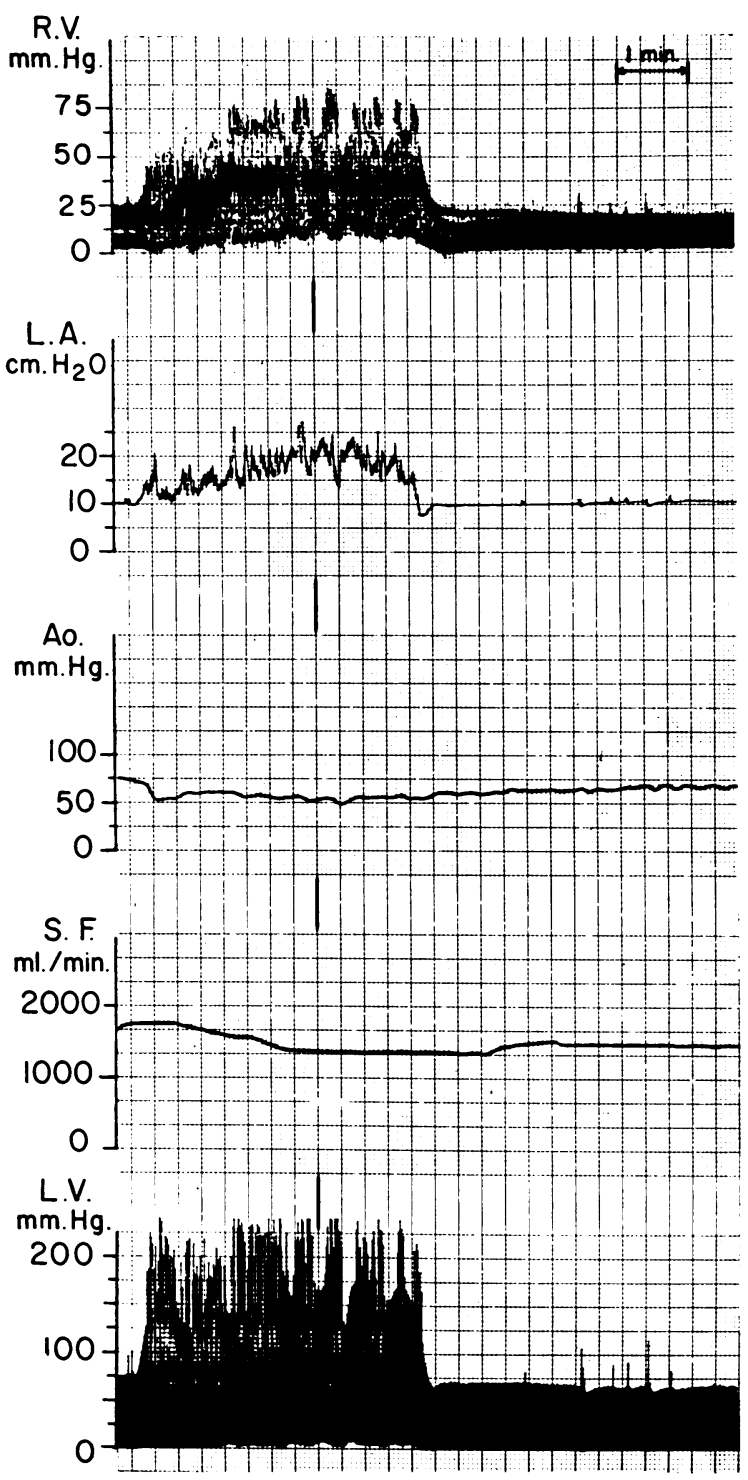

Fig. 3. Dog 1. The effects of elevations of PResSURES IN THE RIGHT VENTRICLE (RV), LEFT ATRIUM (LA) AND LEFT VENTRICLE (LV), ACCOMPANIED BY EXTRASYSTOLES, ON TOTAL VENOUS RETURN, AS MEASURED BY ALTERING SYSTEMIC PERFUSION RATE (S.F.). The latter declined after intracardiac pressures were elevated and returned toward the control levels following the reduction of these pressures.

In five experiments (Dogs 5, 6, 11-13) right ventricular pressure was elevated from average values of $4 / 1$ to $68 / 12 \mathrm{~mm} \mathrm{Hg}$, while left atrial and left ventricular pressures were maintained at relatively constant levels. Peripheral resistance declined by only 0 to 5 per cent, with an average fall of 3 per cent from control levels (Figure 5).
In the entire series of experiments it was observed that the occurrence of ventricular extrasystoles was accompanied by a brief but striking decline in systemic vascular resistance (Figures 3 and $5 \mathrm{~A}$ ).

$I V$. Alterations in leart rate. The effects of the elevations in intracardiac pressures on heart rate were variable and slight (Table I). In seven experiments the rate declined by more than 5 beats per minute; in five experiments it rose by

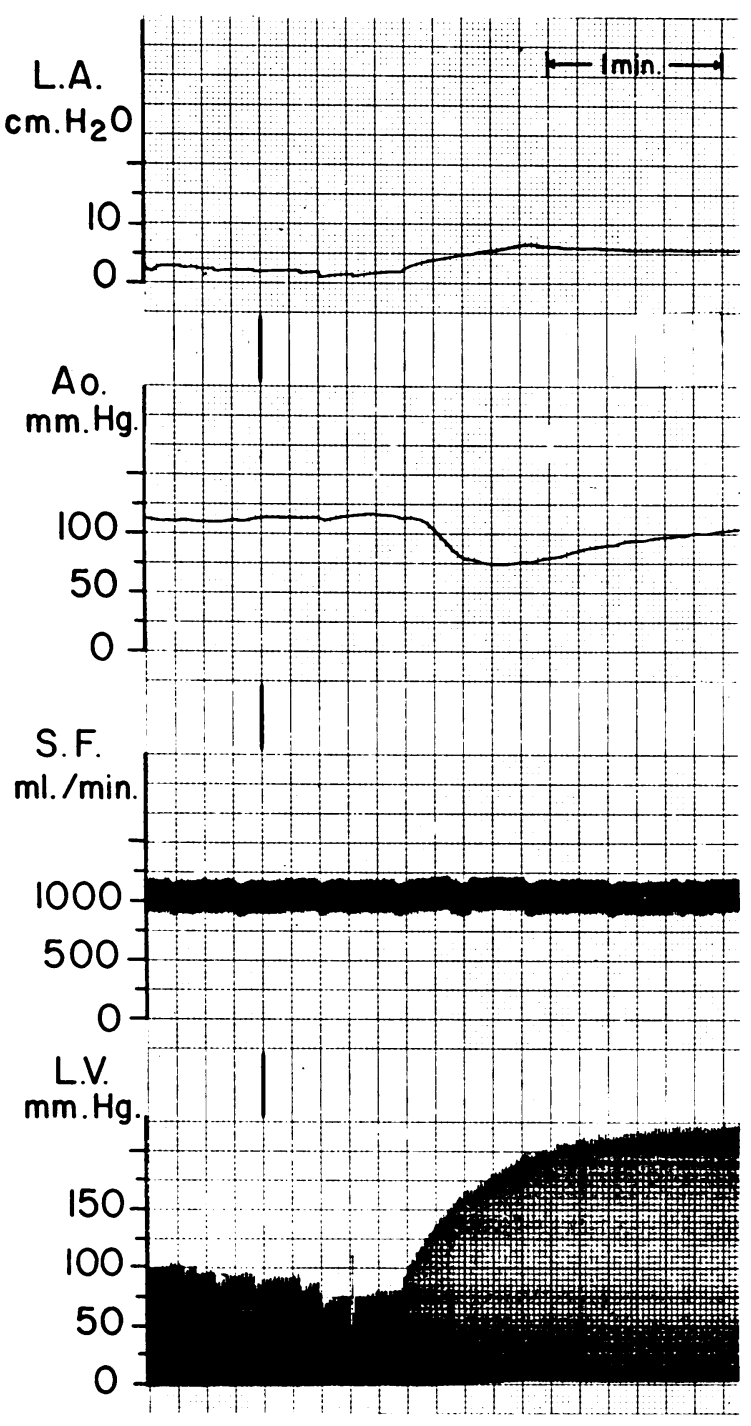

Fig. 4. Dog 17. Alterations in aortic pressure (Ao.) at a constant systemic flow (S.F.) Following ELEVATION OF LEFT VENTRICULAR (LV) SYSTOLIC PRESSURE, ACCOMPANIEd BY A MINIMAL ELEVATION OF LEFT VENTRICULAR DIASTOLIC AND MEAN LEFT ATRIAL (LA) PRESSURE. 

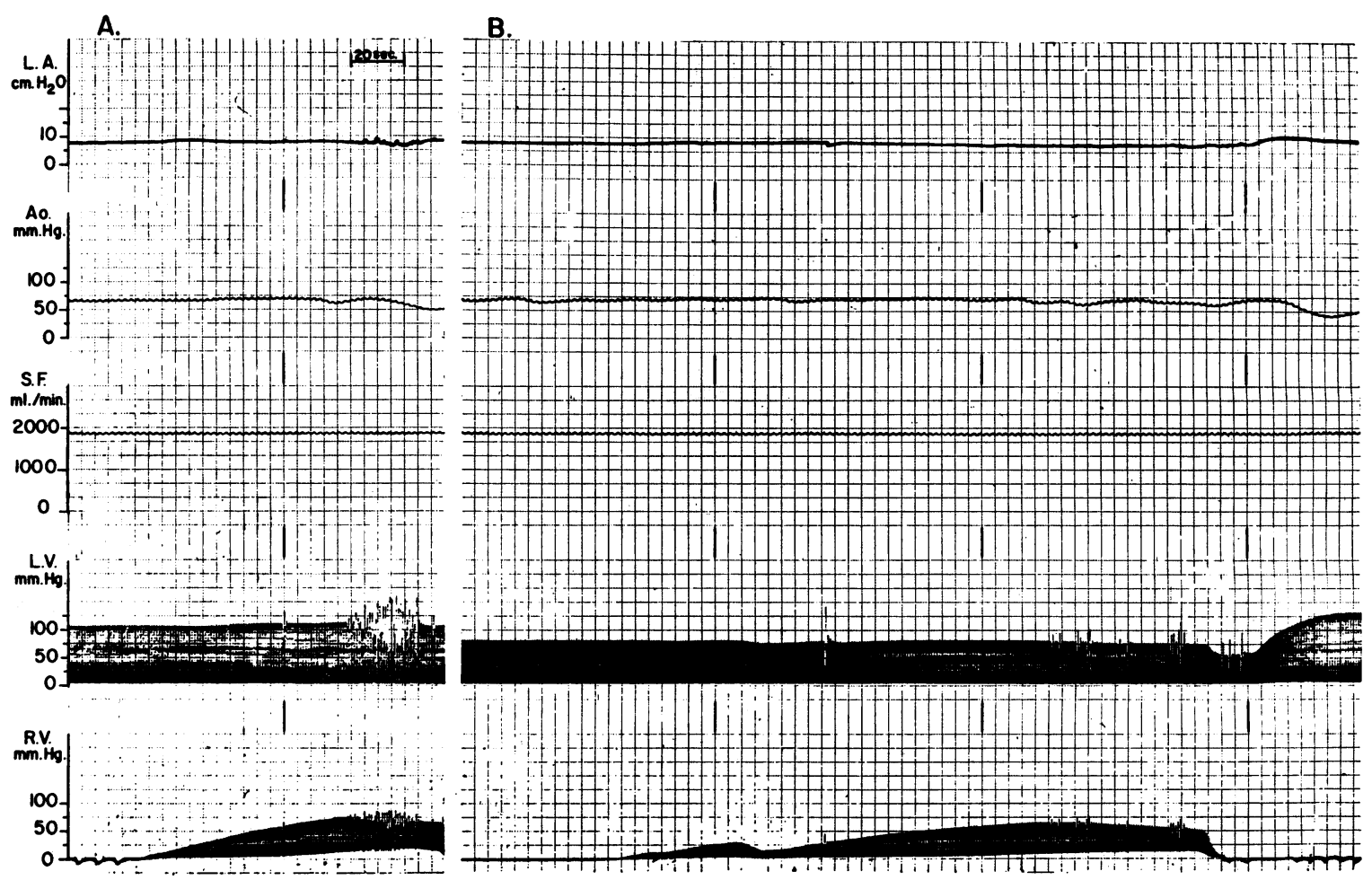

Fig. 5. Dog 6. A. Minimal alerations in aORTic pREsSURe accompanying elevation of Right ventricular PRESSURES. A more marked decline occurs near the end of the tracing following a series of extrasystoles.

B. The efFect of alternately elevating Right ventricular (RV) AND LEFT ventricular (LV) PRESSURES ON AORTIC PRESSURE (Ao.) ARE CONTRASTED. Little change results from gradually elevating RV pressure, but a striking fall occurs when LV pressure is increased.

more than 5 beats per minute; in six it changed less than 5 beats per minute; and in two the changes were inconsistent. The specific chambers in which pressures were elevated did not appear to influence these results.

$V$. Effects of cessation of flow to the heart. In six experiments, when the inflow of blood to the heart was suddenly terminated, left ventricular

TABLE II

Hemodynamic effects of cessation of flow to the heart*

\begin{tabular}{|c|c|c|c|c|c|c|c|}
\hline \multirow{2}{*}{$\begin{array}{l}\text { Dog } \\
\text { no. }\end{array}$} & \multicolumn{2}{|c|}{ LV press. } & \multicolumn{2}{|c|}{ LA press. } & \multicolumn{2}{|c|}{ Ao press. } & \multirow{2}{*}{$\begin{array}{l}\text { Increase } \\
\text { Ao press. }\end{array}$} \\
\hline & A & $\bar{B}$ & A & $\bar{B}$ & A & B & \\
\hline & \multicolumn{2}{|c|}{$m m \mathrm{Hg}$} & \multicolumn{2}{|c|}{$\mathrm{cm} \mathrm{H}_{2} \mathrm{O}$} & \multicolumn{2}{|c|}{$m m ~ H g$} & $\%$ \\
\hline $\begin{array}{r}1 \\
5 \\
6 \\
8 \\
11 \\
113\end{array}$ & $\begin{array}{l}85 / 6 \\
75 / 9 \\
83 / 7 \\
87 / 6 \\
83 / 7 \\
75 / 7\end{array}$ & $\begin{array}{l}6 / 0 \\
1 / 0 \\
1 / 0 \\
8 / 5 \\
1 / 0 \\
0 / 0\end{array}$ & $\begin{array}{l}8 \\
8.5 \\
10 \\
10 \\
10 \\
7.5\end{array}$ & $\begin{array}{l}6 \\
0 \\
6.5 \\
7 \\
6.5 \\
3.5\end{array}$ & $\begin{array}{l}65 \\
70 \\
64 \\
88 \\
94 \\
90\end{array}$ & $\begin{array}{r}98 \\
82 \\
73 \\
113 \\
105 \\
115\end{array}$ & $\begin{array}{l}51 \\
17 \\
14 \\
28 \\
12 \\
20\end{array}$ \\
\hline
\end{tabular}

* Columns A represent observations made just prior to cessation of flow to the heart. Columns B represent observations made following pressure declined abruptly from an average value of $81 / 7 \mathrm{~mm} \mathrm{Hg}$, and reached levels of less than $8 / 5 \mathrm{~mm} \mathrm{Hg}$ within several minutes after cessation of the heart beat. Right ventricular systolic pressure was less than $9 \mathrm{~mm} \mathrm{Hg}$ prior to the cessation of perfusion and showed no significant change (Table II). In each dog systemic vascular resistance increased immediately, continued to rise for approximately 5 minutes and stabilized thereafter (Figure 6). These increases in systemic vascular resistance ranged from 14 to 51 per cent and averaged 25 per cent of the control values.

\section{DISCUSSION}

The innervated, hemodynamically isolated heart preparation employed in these experiments permitted precise study of the effects of altering intracardiac pressures on the separately perfused systemic circulation. Although the use of general anesthesia, an open chest and cardiopulmonary bypass inevitably compromised the reactivity of 


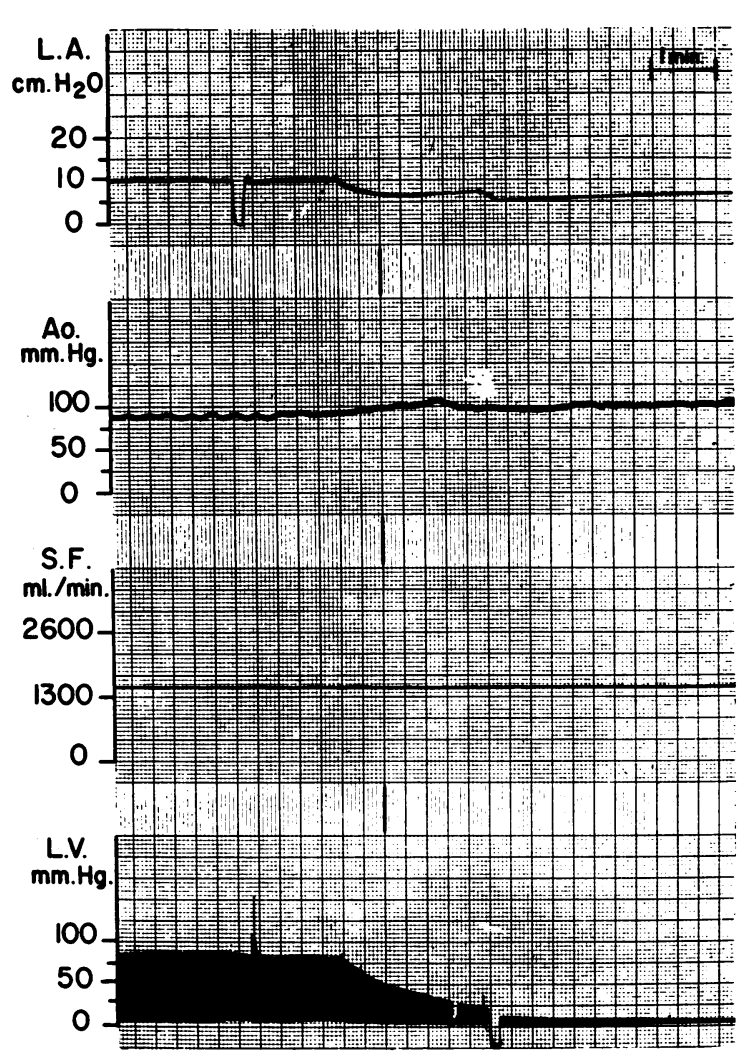

Fig. 6. Dog 8. EFfects on Aortic pressure (Ao.) OF CESSATION OF CARDIAC PERFUSION AND THE RESUlTING DECline IN INTRACARDIAC PRESSURE. Cardiac perfusion was stopped at the instant that the left ventricular and left atrial pressures began to fall. An immediate elevation of aortic pressure is evident.

the preparation, these interventions were found necessary to investigate the nature of the peripheral circulatory changes following alteration of intracardiac pressures.

It was observed that a substantial decline in venous return resulted when pressures in the right and left ventricles were elevated. The significance of these changes in venous return is indicated by the large changes in the output of the extracorporeal pump which were necessary to obviate any alterations in intravascular blood volume. These changes in pump output provide a measurement of the decrease in cardiac output that would have occurred had the heart responded passively to the reflex change in venous return. In addition, when systemic perfusion was maintained constant, elevation of left heart pressures alone, or of both left and right heart pressures, resulted in an expansion of the intravascular blood volume. In- creases in blood volume have also been recently reported by Salisbury, Cross, and Rieben following distention of the left ventricle with a balloon (8). Klussman, Van Citters and Rushmer, on the other hand, did not demonstrate any changes in limb circumference or liver diameter when suction devices were applied to portions of the cardiac walls (17).

The changes in venous return and systemic blood volume following elevations of intracardiac pressures reported herein resemble those that were observed when pressure within the isolated carotid sinuses were elevated or when the vasodilating drug, Arfonad, was administered (12). It was previously suggested that these alterations in venous return and systemic blood volume are most likely due to dilatation of the systemic venous bed (12), because of 1 ) the large magnitude of the alterations in systemic vascular volume which occurred, and 2) the fact that only $15 \mathrm{ml}$ per $\mathrm{kg}$ of blood is estimated to be contained in the arterial and arteriolar vascular beds of the $\operatorname{dog}(18)$. Furthermore, arterial pressure varied inversely with total systemic blood volume, and it is therefore possible that the changes in the volume of the prearteriolar bed were actually opposite in direction to the alterations in total systemic blood volume. From the data presented above, it also appears likely that an inhibition of venous tone resulted from stimulation of the intracardiac baroreceptors. Since splenic volume is known to vary with alterations in sympathetic tone (19), it is of interest that the changes in blood volume resulting from elevating intracardiac pressures were also observed in the dogs that had been splenectomized previously.

Reflexes originating from the left side of the heart were first clearly demonstrated by Aviado and Schmidt (5). In the present experiments, when left ventricular systolic pressure was elevated but only minimal change in left ventricular diastolic and left atrial mean pressures occurred, systemic vascular resistance declined. These observations suggest the presence of left ventricular baroreceptors sensitive to changes in systolic pressure. Indeed, bursts of impulses during early systole have been recorded from cardiac afferent nerve fibers by several investigators $(1,2)$. However, since some enlargement of the left atrium probably accompanied minimal elevations 
of left atrial pressure, the stimulation of left atrial receptors responsive to volume changes (20) cannot be completely excluded except in that experiment (Dog 16) in which isolated left ventricular perfusion resulted in absolutely no change in left atrial pressure. More striking alterations in vascular resistance were induced when left ventricular diastolic and left atrial pressures were elevated above $10 \mathrm{~mm} \mathrm{Hg}$ (Figure 7). Since the hila of the lungs were ligated in all of the experiments carried out on Dog 2, the large pulmonary veins were distended together with the left atrium. Previous studies have suggested that the pulmonary veins $(4,10,11,21)$, as well as the left atrium $(7,20)$ contain baroreceptor endings, and it is likely that receptors in both of these areas participated in the observed reflexes.

Contrary to the observations of others $(4,11)$, only minimal declines in vascular resistance occurred when, in the absence of extrasystoles (Figure 5), pressures in the right side of the heart alone were elevated. However, in the present experiments, ligation of the hila prevented pressure elevation in the smaller pulmonary vessels, which perhaps contain receptors responsible for the decline in peripheral resistance observed by others when right heart pressures were elevated (11). In addition, in the present studies, right ventricular diastolic and atrial pressures were only moderately elevated and provided a less extreme stimulus than that utilized in previous investigations (4). Accordingly, it is suggested from the present experiments that the intracardiac receptors of greatest importance in the control of systemic vascular resistance are those sensitive to elevation of left ventricular diastolic pressure and/or left atrial pressure. It is possible that the ultimate stimulus for these receptors is the stretch that occurs when the volume of the cardiac chambers is increased. However, the possibility that baroreceptors in the coronary vessels are also of importance has not been excluded, since elevation

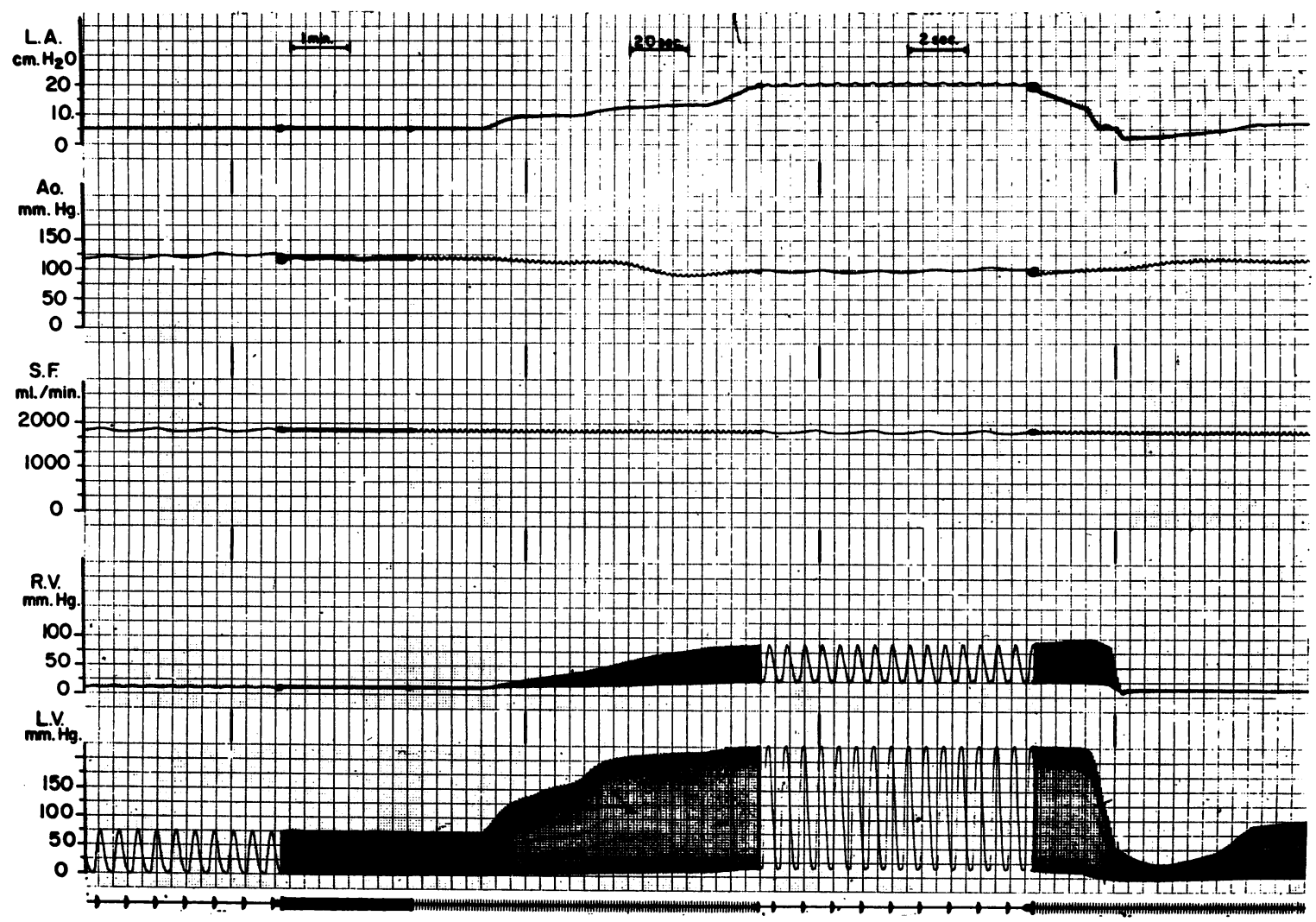

Fig. 7. Dog 2. Tracing Showing the effects on aORTIC pRessure of STEP-Wise elevation of intracardiaC PRESSURES. The most profound decline of aortic pressure occurred following elevation of mean left atrial (LA) pressure above $10 \mathrm{~cm} \mathrm{H}_{2} \mathrm{O}$. 
of left ventricular systolic pressure simultaneously raised the pressure in the coronary system.

It was observed that systemic vascular resistance fell when left ventricular systolic pressure was elevated in the range below the normal systolic blood pressure for the dog. This suggests that the left-sided intracardiac baroreceptors possess a low pressure threshold and, therefore, that these receptors may be continuously activated at normal intracardiac pressures. This possibility receives support from experiments in which rhythmic impulses, synchronous with both ventricular and atrial contractions, were recorded from cardiac afferent fibers $(1,2,9)$. Furthermore, the initial rapid rise in arterial pressure (Figure 6) which occurred following cessation of cardiac perfusion suggests that a continuous inhibitory influence on vascular resistance originating from the heart had been removed; this observation provides additional evidence for tonic activity of the intracardiac receptors. The continued and progressive elevation in arterial pressure, following cessation of cardiac perfusion, however, may have resulted from stimulation by anoxia of receptors in the myocardium or coronary arteries.

In interpreting the action of reflexes originating from intracardiac receptors, the important effects of extrasystoles must be emphasized. It was observed in the course of these experiments that whenever extrasystoles occurred, whether during right- or left-sided pressure elevation, a striking decline in vascular resistance took place. This finding suggests that the intracardiac receptors, like those in the carotid sinus (22), are activated by rapid fluctuations in stimulation, regardless of the mean level of the stimulus applied. The occurrence of extrasystoles during elevations in right heart pressure thus make interpretation of subsequent reflex changes difficult, and may help to explain the results obtained by some previous investigators $(4,11)$.

The reflex effects of the intracardiac baroreceptors may be of importance in a variety of physiologic and pathologic circumstances. It would seem likely that they operate in conjunction with the sinoaortic mechanism in the regulation of both arteriolar and venous tone and therefore of arterial pressure and cardiac output. In addition, when intracardiac pressures alone are elevated, as in the presence of congestive heart failure or valvular stenosis, the resulting arteriolar and venous dilatation could serve to decrease the hemodynamic burden imposed on the heart both by diminishing systemic pressure and by decreasing venous return.

\section{SUMMARY}

The effects of alterations of intracardiac pressures on total venous return, system vascular volume and peripheral vascular resistance were studied in an experimental canine preparation. The systemic vascular bed was perfused, using an extracorporeal circulation, while pressures were independently varied in the innervated, but hemodynamically isolated heart.

Elevation of intracardiac pressure (either in all four chambers or only in the left side of the heart) in ten dogs resulted in an augmentation of systemic vascular volume which averaged $120 \mathrm{ml}$. In the three dogs in which the venous return was measured, it declined by an average of 25 per cent from the control levels. Significant decreases in systemic vascular resistance were observed when left ventricular systolic pressures were elevated, when left ventricular diastolic and mean left atrial pressures were also elevated, or when extrasystoles occurred. Only minimal alterations in vascular resistance were observed to accompany elevation of right heart pressures alone.

\section{REFERENCES}

1. Whitteridge, D. Afferent nerve fibres from the heart and lungs in the cervical vagus. J. Physiol. (Lond.) 1948, 107, 496.

2. Paintal, A. S. A study of ventricular pressure receptors and their role in the Bezold reflex. Quart. J. exp. Physiol. 1955, 40, 348.

3. Daly, I. deB., and Verney, E. B. Localisation of receptors involved in reflex regulation of heart rate. J. Physiol. (Lond.) 1927, 62, 330.

4. Aviado, D. M., Jr., Li, T. H., Kalow, W., Schmidt, C. F., Turnbull, G. L., Peskin, G. W., Hess, M. E., and Weiss, A. J. Respiratory and circulatory reflexes from the perfused heart and pulmonary circulation of the dog. Amer. J. Physiol. 1951, 165, 261.

5. Aviado, D. M., Jr., and Schmidt, C. F. Cardiovascular and respiratory reflexes from the left side of the heart. Amer. J. Physiol. 1959, 196, 726.

6. Heymans, C., and Neil, E. Reflexogenic Areas of the Cardiovascular System. Boston, Little, Brown, 1958.

7. Doutheil, U., and Kramer, K. Über die Differenzierung kreislaufregulierender Reflexe aus dem 
linken Herzen. Pflüg. Arch. ges. Physiol. 1959, 269, 114 .

8. Salisbury, P. F., Cross, C. E., and Rieben, P. A. Reflex effects of left ventricular distention. Circulat. Res. 1960, 8, 530.

9. Amann, A., and Schaefer, H. Über sensible Impulse im Herznerven. Pflüg. Arch. ges. Physiol. 1943, 246, 757.

10. Churchill, E. D., and Cope, O. The rapid shallow breathing resulting from pulmonary congestion and edema. J. exp. Med. 1929, 49, 531.

11. Daly, I. deB., Ludany, G., Todd, A., and Verney, E. B. Sensory receptors in the pulmonary vascular bed. Quart. J. exp. Physiol. 1937, 27, 123.

12. Ross, J., Jr., Frahm, C. J., and Braunwald, E. The influence of the carotid baroreceptors and of vasoactive drugs on systemic vascular volume and venous distensibility. Circulat. Res. 1961, 9, 75.

13. Ross, J., Jr., Waldhausen, J. A., and Braunwald, E. Studies on digitalis. I. Direct effects on peripheral vascular resistance. J. clin. Invest. 1960, 39, 930.

14. Shipley, R. E., and Wilson, C. An improved recording rotameter. Proc. Soc. exp. Biol. (N. Y.) 1951, 78, 724.

15. Waldhausen, J. A., Ross, J., Jr., Lombardo, C. R., Cooper, T., Gilbert, J. W., and Morrow, A. G. Flow and volume regulation during cardiopulmo- nary bypass: The use of an electromagnetic flowmeter and a device for the automatic control of oxygenator volume. Trans. Amer. Soc. artif. intern. Organs 1959, 5, 172.

16. Ross, J., Jr., Braunwald, E., and Waldhausen, J. A. Studies on digitalis. II. Extracardiac effects on venous return and on the capacity of the peripheral vascular bed. J. clin. Invest. 1960, 39, 937.

17. Klussman, F. W., Van Citters, R. L., and Rushmer, R. F. Cardiovascular effects of distortion of stretch receptors in the cardiac walls. Fed. Proc. 1960, 19, 92.

18. Green, H. O. in Medical Physics, O. Glasser, Ed. Chicago, Year Book Publishers, 1944, vol. 1, p. 210.

19. Holtz, P., Bachmann, F., Engelhardt, A., and Greeff, K. Die Milzwirkung des Adrenalins und Arterenols. Pflüg. Arch. ges. Physiol. 1952, 255, 232.

20. Paintal, A. S. A study of right and left atrial receptors. J. Physiol. (Lond.) 1953, 120, 596.

21. Schwiegk, H. Der Lungenentlastungsreflex. Pflüg. Arch. ges. Physiol. 1935, 236, 206.

22. Ead, H. W., Green, J. H., and Neil, E. A comparison of the effects of pulsatile and non-pulsatile blood flow through the carotid sinus on the reflexogenic activity of the sinus baroreceptors in the cat. J. Physiol. (Lond.) 1952, 118, 509. 